Article

\title{
The Activation of Ti-Zr-V-Hf Non-Evaporable Getter Films with Open-Cell Copper Metal Foam Substrates
}

\author{
Jie Wang ${ }^{1}$, Jing Zhang ${ }^{1}$, Yong Gao ${ }^{1}$, Yaocheng $\mathrm{Hu}^{1}{ }^{1}$, Zhiming You ${ }^{1}{ }^{\mathbb{D}}$, Yupeng $\mathrm{Xie}^{1}{ }^{1}$, Haipeng $\mathrm{Li}^{1}$, \\ Yue $\mathrm{Wu}^{2}$, Shanghui Yang ${ }^{1}$, Dengwang Wang ${ }^{1}$, Sheng Wang ${ }^{1, *}$ and Zhanglian $\mathrm{Xu}^{1, *}$ \\ 1 Shaanxi Engineering Research Center of Advanced Nuclear Energy \& Shaanxi Key Laboratory of Advanced \\ Nuclear Energy and Technology \& School of Energy and Power Engineering, Xi'an Jiaotong University, \\ Xi'an 710049, China; wangjie1@xjtu.edu.cn (J.W.); zhangjing1108@stu.xjtu.edu.cn (J.Z.); \\ gaoyong1108@stu.xjtu.edu.cn (Y.G.); hyc1997@stu.xjtu.edu.cn (Y.H.); youzm19960311@stu.xjtu.edu.cn (Z.Y.); \\ xieyupeng@stu.xjtu.edu.cn (Y.X.); lihaipeng@xjtu.edu.cn (H.L.); y574055234@stu.xjtu.edu.cn (S.Y.); \\ wdw21s@163.com (D.W.) \\ 2 Department of Engineering Physics, Tsinghua University, Beijing 100084, China; \\ y-wu20@mails.tsinghua.edu.cn \\ * Correspondence: shengwang@mail.xjtu.edu.cn (S.W.); xuzhanglian@xjtu.edu.cn (Z.X.)
}

Received: 20 September 2020; Accepted: 14 October 2020; Published: 18 October 2020

\begin{abstract}
Secondary electron emission (SEE) inhibition and vacuum instability are two important issues in accelerators that may induce multiple effects in accelerators, such as power loss and beam lifetime reduction. In order to mitigate SEE and maintain high vacuum simultaneously, open-cell copper metal foam (OCMF) substrates with Ti-Zr-V-Hf non-evaporable getter (NEG) coatings are first proposed, and the properties of surface morphology, surface chemistry and secondary electron yield (SEY) were analyzed for the first time. According to the experimental results tested at $25{ }^{\circ} \mathrm{C}$, the maximum SEY $\left(\delta_{\max }\right)$ of OCMF before and after Ti-Zr-V-Hf NEG film deposition were 1.25 and 1.22 , respectively. The XPS spectra indicated chemical state changes of the metal elements $(\mathrm{Ti}, \mathrm{Zr}$, $\mathrm{V}$ and Hf) of the Ti-Zr-V-Hf NEG films after heating, suggesting that the NEG films can be activated after heating and used as getter pumps.
\end{abstract}

Keywords: accelerators; surface morphology; surface chemical states

\section{Introduction}

For the search of possible dark matter (DM) and the study of Higgs physics, several high-energy and high-luminosity accelerators such as the future circular collider (FCC) and the super proton-proton collider (SPPC) have been proposed, with their vacuum systems facing two main challenges of high vacuum gradient and the electron cloud (EC) issues.

On one hand, to reduce the ultimate pressure and vacuum gradient as well as maintain the vacuum stability in accelerators, non-evaporable getter (NEG) films such as Ti-Zr-V films [1-3] have been deposited on the inner surface of the vacuum pipes or getter pumps in vacuum systems [2,4], thanks to their distributed pumping properties [3,5-7]. On the other hand, to suppress electron clouds in vacuum pipes, various solutions, such as the laser ablation technique [8], artificially grooving surfaces [9], carbon coatings [10] and TiN films [11], etc., have been developed. Generally speaking, previous studies have focused on these two issues separately. A solution for both issues of high vacuum gradient and EC effect has rarely been mentioned before.

NEG films are usually deposited on a flat metal surface. To further improve the residual gas absorption capacity of the film, porous metal substrates with a high contact surface area can be used. Meanwhile, in consideration of the EC effect, the SEY of porous metal substrates can be optimized. 
Porous materials [12-14] have been developed rapidly over the last decades because of their excellent properties [15-18], such as large specific surface area [19]. As a porous material, porous metals can be used in electronics and communication [20], energy [21,22], transportation [23,24], bioengineering industries [25-27], and so on. With the advantage of porous structures, foam materials can be used as supports for composites by providing a large contact area for the fillers. For example, a film containing ilmenite has been proposed for depositing on foam glass to improve its absorption properties for electromagnetic radiation with high frequency due to its low reflection and light weight [28]. Moreover, Leong et al. introduced and optimized the pore density of aluminum foams to further improve heat transfer in electronic systems, taking advantage of the high thermal conductivity and large contact surface area of metal foams [29].

It has been reported that the Ti-Zr-V-Hf NEG coating has a lower activation temperature of about $150^{\circ} \mathrm{C}$ [30]. In this study, open-cell copper metal foam (OCMF) was initially used as the substrate for Ti-Zr-V-Hf NEG coatings to mitigate SEE and provide a good performance of pumping in a vacuum. The structural properties, secondary electron yields (SEYs) and activation process of Ti-Zr-V-Hf NEG films with OCMF substrates were investigated for the first time.

\section{Experiments and Methods}

\subsection{Characterization Methods}

The surface morphologies of the OCMF substrates before and after film deposition were determined using a JEOL 7800F Schottky field scanning electron microscope (SEM, Japan Electron Optics Laboratory, Tokyo, Japan) and Zeiss GeminiSEM 500 emission scanning electron microscope (FE-SEM, Carl Zeiss $\mathrm{GmbH}$, Hallbergmoos, Germany) with an energy dispersive spectrometer (EDS) system to characterize the cross-section and surface morphologies and the distribution maps of related elements. The secondary electron emission properties of the samples were tested using the SEY test equipment. During the SEY tests, the beam diameter and beam current were about $2 \mathrm{~mm}$ and $8 \mathrm{nA}$, respectively. For the SEY and XPS tests, the average heating rates were about $1.2 \mathrm{~min} /{ }^{\circ} \mathrm{C}$ at a pressure of about $1 \times 10^{-7} \mathrm{~Pa}$. Surface compositions tests were carried out with an X-ray photoelectron spectroscope (Thermo Fisher ESCALAB $\mathrm{Xi}^{+}$, Thermo Fisher Scientific, Waltham, MA, USA), which was calibrated with a binding energy of C1s peak of $284.8 \mathrm{eV}$.

\subsection{Sample Preparation}

The OCMF substrates with the dimension of $10 \mathrm{~mm} \times 10 \mathrm{~mm} \times 1 \mathrm{~mm}$ were purchased from Kunshan Longshengbao Electronic Materials Co., Ltd. (Kunshan, China) and prepared by the metal deposition method. The copper was deposited on the open-cell polymer frameworks, followed by polymer elimination and materials sintering.

Before the Ti-Zr-V-Hf NEG coating deposition, the OCMF substrates with a pore size of 0.1 $\mathrm{mm}$ were ultrasonically rinsed in acetone and then in absolute ethyl alcohol for $10 \mathrm{~min}$, respectively. Then the TiHf film coatings were deposited on the OCMF substrates by DC sputtering using Ar gas with a purity of $99.999 \%$. The target material was made of $\mathrm{Ti}, \mathrm{Zr}, \mathrm{V}$ and $\mathrm{Hf}$ elements with an atomic number ratio of 1:1:1:1. Typical film deposition parameters were a working pressure of $0.5 \mathrm{~Pa}$, a discharge power of $280 \mathrm{~W}$, a gas flow of $20 \mathrm{Sccm}$, a sputtering rate of $1.39 \mathrm{~nm} / \mathrm{s}$ and a base pressure of $5.8 \times 10^{-4} \mathrm{~Pa}$. The temperature of the sample disk increased from $25^{\circ} \mathrm{C}$ to $40^{\circ} \mathrm{C}$ during Ti-Zr-V-Hf non-evaporable getter film deposition. Three Ti-Zr-V-Hf non-evaporable getter films with open-cell copper metal foam substrate samples prepared by the same film deposition parameters were used for the same tests, such as the SEM tests. The photos of the OCMF substrates before and after film deposition are shown in Figure 1a,b. The model of the DC sputtering deposition machine is shown schematically in Figure 1c. Silicon wafers were used to evaluate the thickness of the Ti-Zr-V-Hf NEG coatings on the porous OCMF substrates, which was $2.48 \mu \mathrm{m}$, as shown in Figure $1 \mathrm{~d}$. 


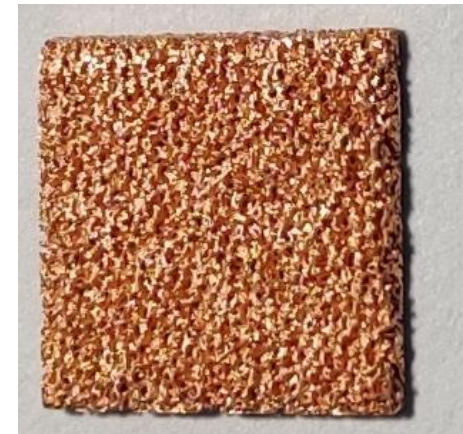

(a)

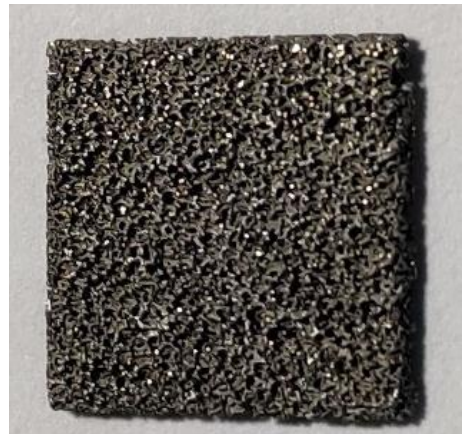

(b)

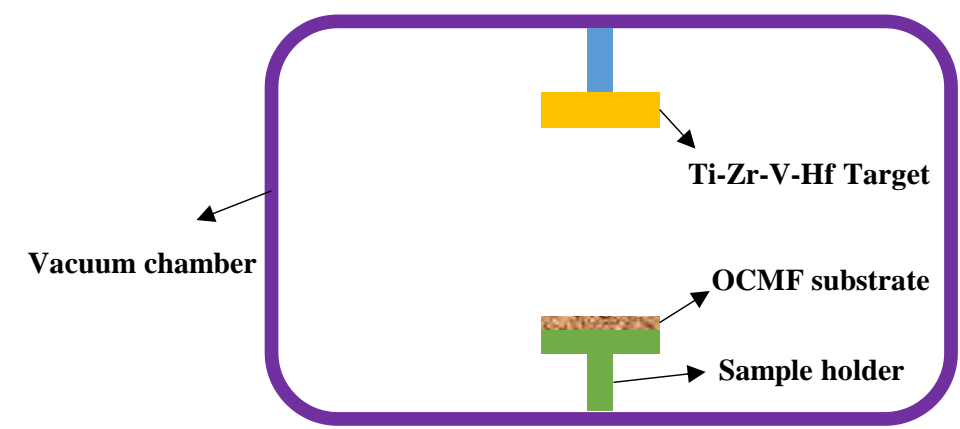

(c)

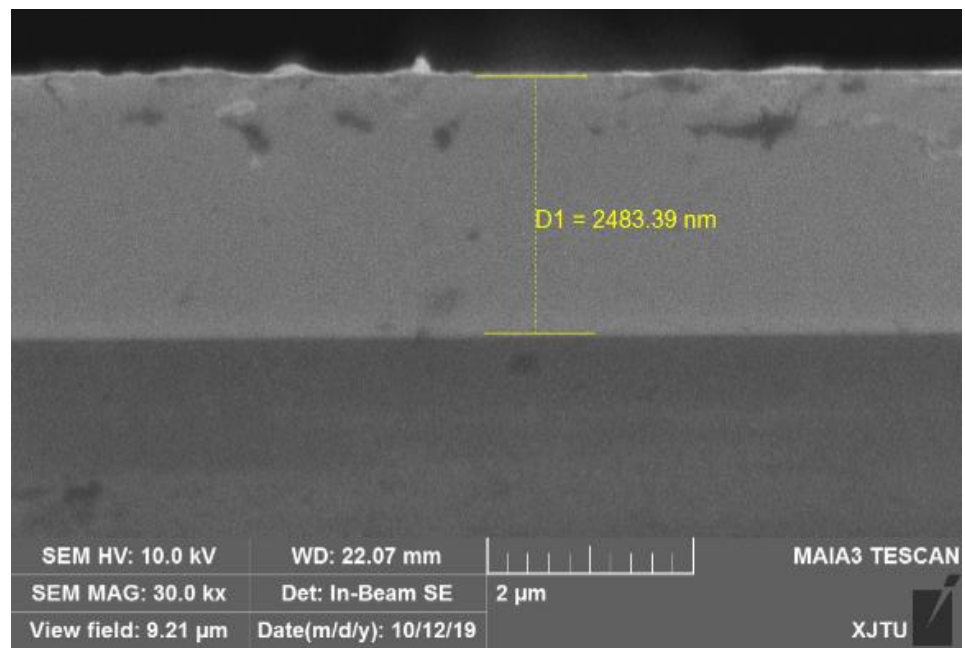

(d)

Figure 1. The photos of the open-cell copper metal foam (OCMF) substrates with the pore size of 0.1 $\mathrm{mm}$ (a) before and (b) after film deposition. (c) The schematic of the DC sputtering deposition machine. (d) The SEM cross-section images of the Ti-Zr-V-Hf film on silicon substrates.

\section{Results and Discussion}

\subsection{Surface Morphology}

The surface morphologies of OCMF substrates with a pore size of $0.1 \mathrm{~mm}$ are shown in Figure 2a-c with different magnifications. The wave-like structures, as shown in Figure 2a, appeared on the surface of the OCMF substrates. At the same time, island-like structures formed on the surface of the Ti-Zr-V-Hf film-coated OCMF substrates, as manifested in Figure $2 \mathrm{~d}$ with the SEM image magnifications of 30,000 $\times$, which may have induced the roughness increase compared to that of the uncoated OCMF substrates in Figure 2a. 


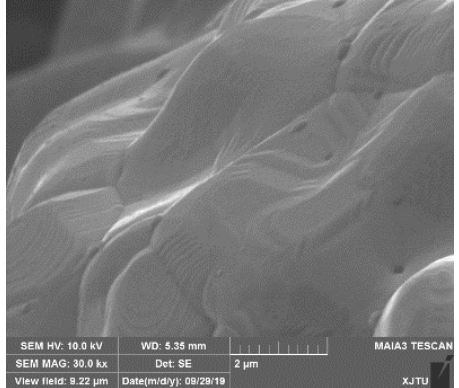

(a)

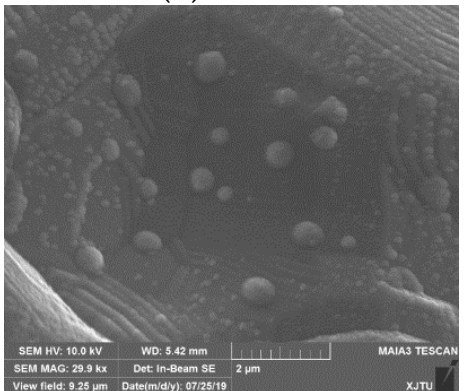

(d)

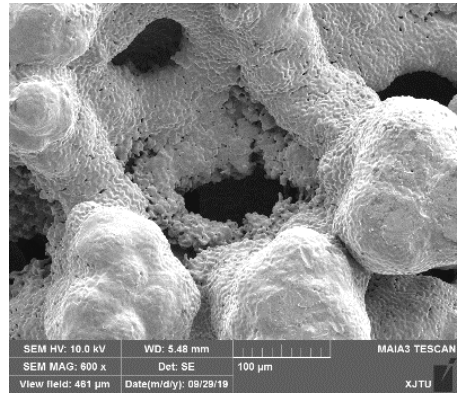

(b)

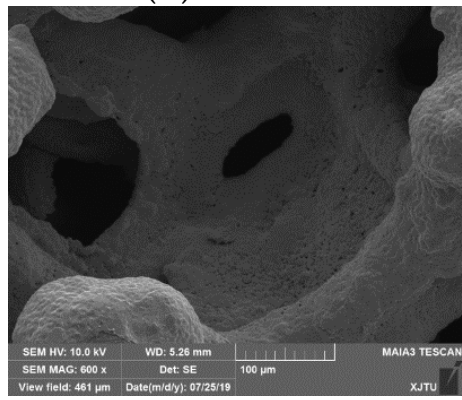

(e)

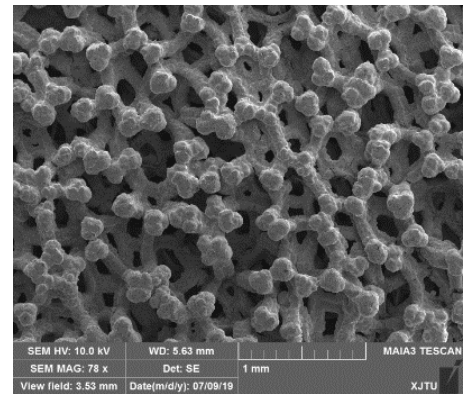

(c)

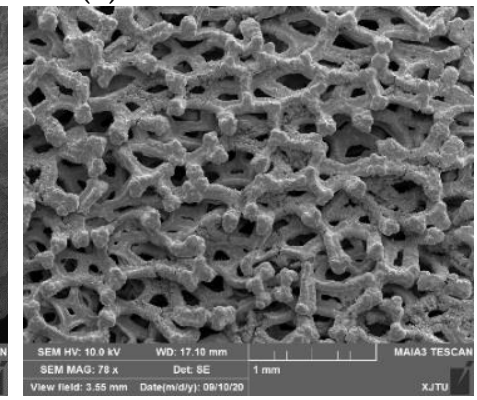

$(\mathbf{f})$

Figure 2. The SEM images of the OCMF substrates and Ti-Zr-V-Hf-coated OCMF. (a), (b) and (c) are the surface morphologies of the OCMF substrates with different magnifications of $30,000 \times, 600 \times$ and $78 \times$. (d), (e) and (f) are the surface morphologies of Ti-Zr-V-Hf-coated OCMF substrates with different magnifications of $30,000 \times, 600 \times$ and $78 \times$.

To analyze the element distributions of the OCMF substrates before and after film deposition, SEM and EDS analyses were performed. A cross-section SEM image of the OCMF substrates is shown in Figure 3a. The EDS results indicated the existence of three elements $(\mathrm{Cu}, \mathrm{C}$ and $\mathrm{O})$ on the cross-section of the OCMF substrates (Figure $3 \mathrm{~b}-\mathrm{d}$ ). This may indicate that the OCMF substrate surface was partially oxidized during air exposure.

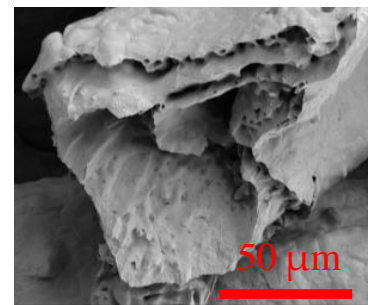

(a) SEM

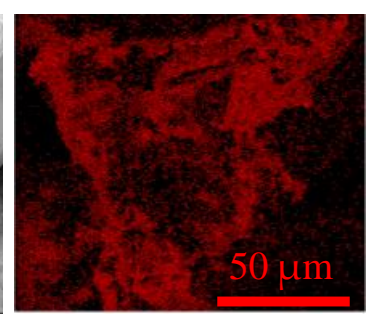

(b) $\mathrm{Cu}$

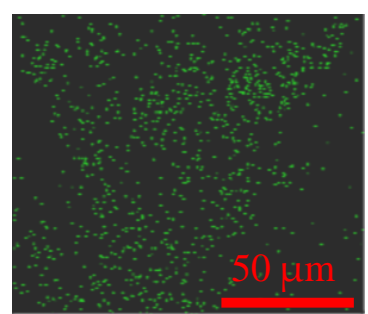

(c) $\mathrm{O}$

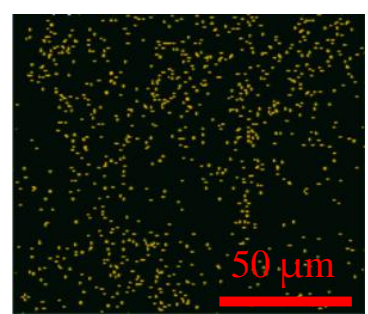

(d) $\mathrm{C}$

Figure 3. The cross-section SEM images of the OCMF substrates (a) with the corresponding elemental distribution maps for $\mathrm{Cu}(\mathbf{b}), \mathrm{O}(\mathbf{c})$ and $\mathrm{C}(\mathbf{d})$.

The surface EDS analysis was conducted to analyze the element distributions of the Ti-Zr-V-Hf film shown in Figure 4a, with relevant maps shown in Figure $4 \mathrm{~b}-\mathrm{h}$. It can be seen that Ti, Zr, V and Hf elements had a uniform distribution, while the Cu element was not found on the surface. This may indicate that the OCMF substrate surface was basically fully covered by the Ti-Zr-V-Hf NEG film. A small quantity of the element $\mathrm{O}$ was detected, probably due to the air exposure during sample transfer, as shown in Figure 4c. Moreover, the elements of $\mathrm{C}$ and $\mathrm{O}$ may have been contributed by adventitious carbon or hydrocarbons. 


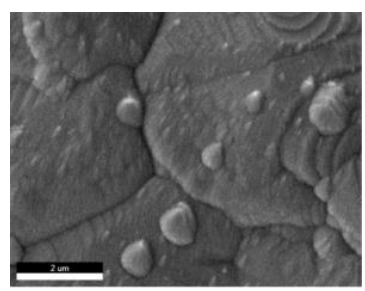

(a) SEM

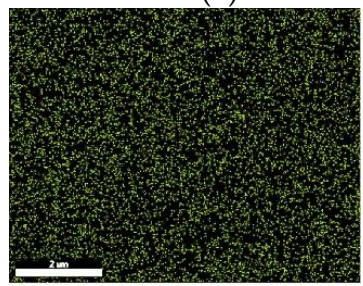

(e) $\mathrm{Ti}$

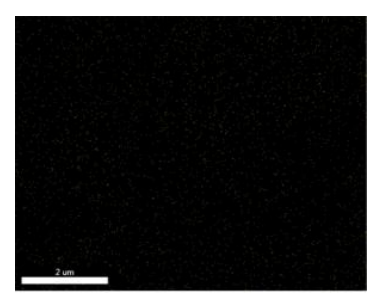

(b) $\mathrm{Cu}$

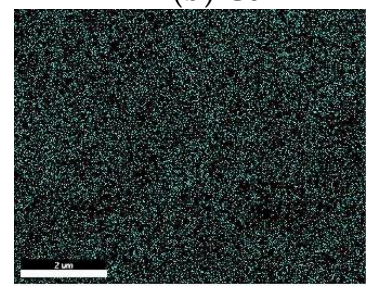

(f) $\mathrm{Zr}$

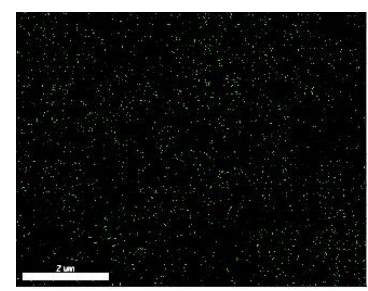

(c) $\mathrm{O}$

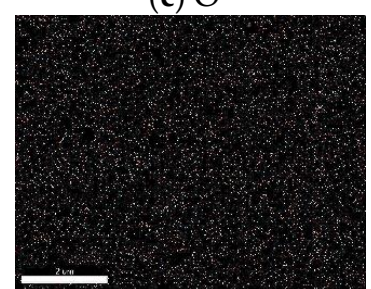

(g) V

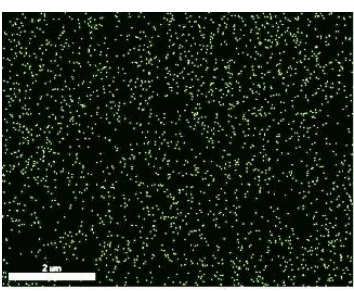

(d) C

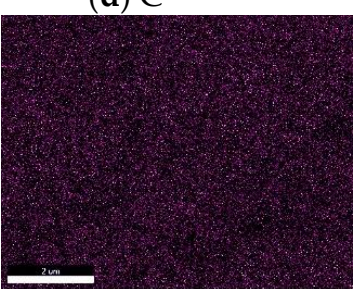

(h) Hf

Figure 4. The surface SEM images of the Ti-Zr-V-Hf film with OCMF substrates (a) and corresponding $\mathrm{Cu}(\mathbf{b}), \mathrm{O}(\mathbf{c}), \mathrm{C}(\mathbf{d}), \mathrm{Ti}(\mathbf{e}), \mathrm{Zr}(\mathbf{f}), \mathrm{V}(\mathbf{g})$ and Hf (h) distribution maps. Scale bar $2 \mu \mathrm{m}$.

\subsection{SEY}

As shown in Figure 5 , the $\delta_{\max }$ of the OCMF substrates before and after Ti-Zr-V-Hf film deposition with a thickness of $2.48 \mu \mathrm{m}$ were 1.25 and 1.22 (tested at $25^{\circ} \mathrm{C}$ ), with a corresponding primary electron energy of $300 \mathrm{eV}$ and $500 \mathrm{eV}$, respectively. The $\delta_{\text {max }}$ of Ti-Zr-V-Hf film with OCMF substrates after heating in a vacuum (at $100{ }^{\circ} \mathrm{C}$ for $2 \mathrm{~h}$ and then $150{ }^{\circ} \mathrm{C}$ for $2 \mathrm{~h}$ ) was 1.20 . It can be seen that the $\delta_{\max }$ of the coated OCMF substrates decreased about 0.03 , compared to that of the uncoated one. Under the condition of heating in a vacuum, the $\delta_{\max }$ of Ti-Zr-V-Hf-coated OCMF further decreased to 1.20, which may be ascribed to surface chemical state changes during the heating process.

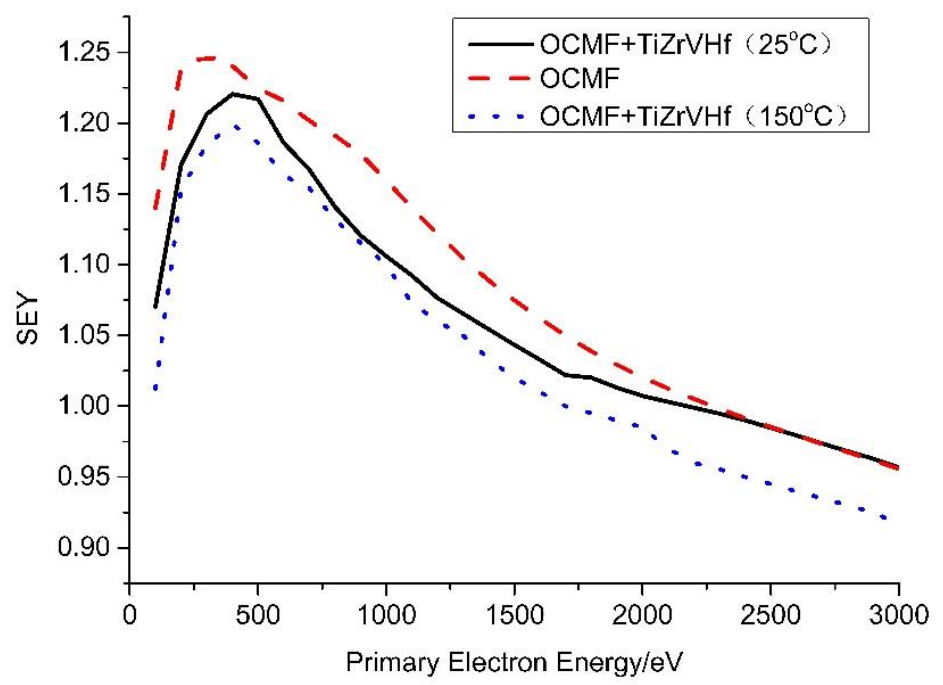

Figure 5. Secondary electron yield (SEY) curves of OCMF substrates and Ti-Zr-V-Hf film-coated OCMF tested at $25^{\circ} \mathrm{C}$ and $150{ }^{\circ} \mathrm{C}$.

As reported by Baglin et al. [31,32], the $\delta_{\max }$ of flat copper was about 1.9-2.5. Compared to the $\delta_{\text {max }}$ of flat copper, that of the OCMF substrates decreased about 0.65-1.25. The electron cloud threshold for large hadron collider (LHC) arcs and SPPC are $\delta_{\max }<1.5$ and $\delta_{\max }<1.2$, respectively [33,34]. Therefore, OCMF coated with Ti-Zr-V-Hf NEG film can be considered for application in the vacuum systems of 
accelerators. However, the $\delta_{\max }$ less than 1 would be better for electron cloud mitigation and power dissipation reduction in the cryogenic region of the vacuum chambers.

\subsection{Surface Chemical States Variation during Activation}

According to the XPS survey scan of the Ti-Zr-V-Hf film tested at $25{ }^{\circ} \mathrm{C}$ shown in Figure 6 , it has a metal element ratio of $2.3(\mathrm{Ti}): 2.7(\mathrm{Zr}): 1.0(\mathrm{~V}): 1.7$ (Hf). After exposure in air, the NEG films need to be reactivated after heating treatment at a certain temperature in an ultrahigh vacuum to recover the pumping ability. During the NEG film activation process, the oxygen present in the surface passivation layer is mainly diffused into the vacuum and deep inside the film. For the activation of Ti-Zr-V-Hf NEG film with OCMF substrates, it was heated at $100{ }^{\circ} \mathrm{C}$ for $2 \mathrm{~h}$, and then at $150{ }^{\circ} \mathrm{C}$ for $2 \mathrm{~h}$ during the XPS tests. The binding energy spectra of Ti, $\mathrm{Zr}, \mathrm{V}$ and $\mathrm{Hf}$ elements of the film sample tested at $25^{\circ} \mathrm{C}$ and then at $150^{\circ} \mathrm{C}$ are shown in Figure 7a-h. During NEG film activation, the Ti 2p, Zr 3d, V 2p and Hf $4 \mathrm{f}$ peak shifts occurred. The XPS spectra showed distinct variations when the Ti-Zr-V-Hf NEG film surface became activated after heating (see Figure 7).

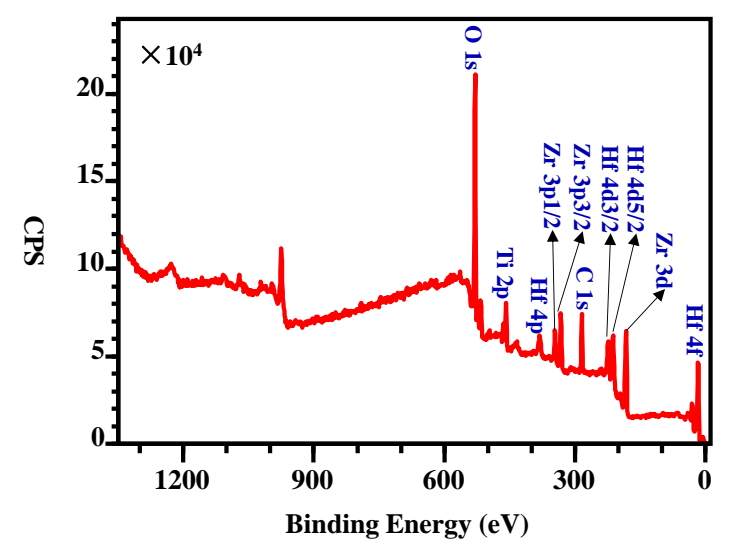

Figure 6. The XPS survey scan of the Ti-Zr-V-Hf film at $25^{\circ} \mathrm{C}$.

The high-resolution photoelectron spectrum of Ti in Figure 7a indicates that Ti metal was basically fully oxidized before heating, which was mainly composed of titanium sub-oxide (Ti-sub) and titanium oxide $\left(\mathrm{Ti}^{4+}\right)$ with the concentrations of 84.5 at $\%$ and 13.8 at $\%$. According to the previous results, the components of $454.0 \mathrm{eV}$ [35-37] and $458.7 \mathrm{eV}$ [38-40] can attribute to the Ti metal and $\mathrm{Ti}^{4+}$, respectively. However, after being activated at $150{ }^{\circ} \mathrm{C}$, the Ti metal appeared to have a concentration of $2.41 \%$. Moreover, the content ratio of $\mathrm{Ti}^{4+}$ decreased progressively from 84.5 at $\%$ to 48.6 at $\%$, and that of Ti-sub increased from 13.8 at $\%$ to $49.1 \mathrm{at} \%$, as shown in Figure $7 \mathrm{a}, \mathrm{b}$.

Figure 7c,d illustrates the $\mathrm{Zr} 3 \mathrm{~d}$ peaks of the Ti-Zr-V-Hf film before and after heating, respectively. The analysis of these two spectra indicates that: (1) the peaks at $182.4 \mathrm{eV}$ and $184.7 \mathrm{eV}$ in Figure $7 \mathrm{c}$ can be ascribed to the state of zirconium oxide $\left(\mathrm{Zr}^{4+}\right)$ [41]. Based on the spectrum of $\mathrm{Zr}$ tested at $25^{\circ} \mathrm{C}$, the $\mathrm{Zr}$ metal on the surface of the Ti-Zr-V-Hf film was basically fully oxidized. (2) At the same time, the zirconium sub-oxide and zirconium metal appeared after heating, with the content ratios of 89.4 at $\%$ and $10.6 \%$, respectively. The heating for the Ti-Zr-V-Hf NEG film activation resulted in the oxidation state change of zirconium.

The vanadium XPS spectrum of Figure $7 \mathrm{e}$ tested at $25^{\circ} \mathrm{C}$ demonstrate that the $\mathrm{V} 2 \mathrm{p}$ were associated with $\mathrm{V}(0), \mathrm{V}(\mathrm{II}), \mathrm{V}(\mathrm{III}), \mathrm{V}(\mathrm{IV})$ and $\mathrm{V}(\mathrm{V})$, with the corresponding content ratios of 0.5 at $\%, 4.1 \mathrm{at} \%, 27.0$ at $\%, 54.0$ at $\%$ and 14.4 at $\%$, respectively. Nevertheless, the vanadium XPS spectrum after heating tested at $150{ }^{\circ} \mathrm{C}$, is composed of $\mathrm{V}(0), \mathrm{V}(\mathrm{II}), \mathrm{V}(\mathrm{III}), \mathrm{V}(\mathrm{IV})$ and $\mathrm{V}(\mathrm{V})$ oxide multiplet peaks with the atom ratios of 57.5 at $\%, 27.1$ at $\%, 14.0$ at $\%, 0.5$ at $\%$ and 0.9 at $\%$, respectively, as shown in Figure $7 f$. It can be seen that the atom ratios of $\mathrm{V}(0)$ and $\mathrm{V}(\mathrm{II})$ increased significantly, and those of $\mathrm{V}(\mathrm{III}), \mathrm{V}(\mathrm{IV})$, and $\mathrm{V}(\mathrm{V})$ decreased distinctly during the Ti-Zr-V-Hf NEG film activation. 


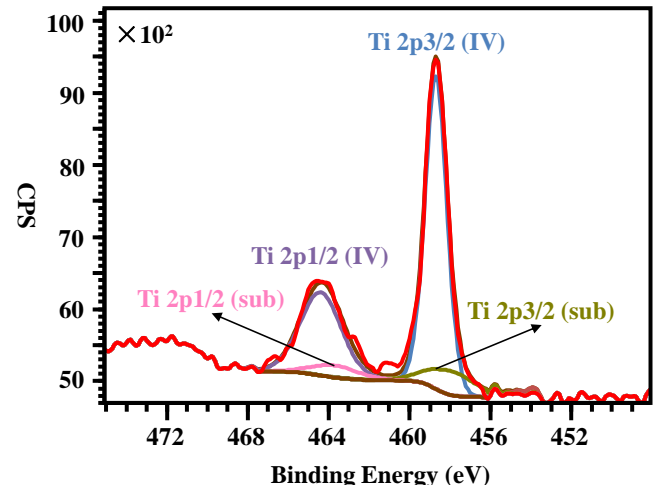

(a)

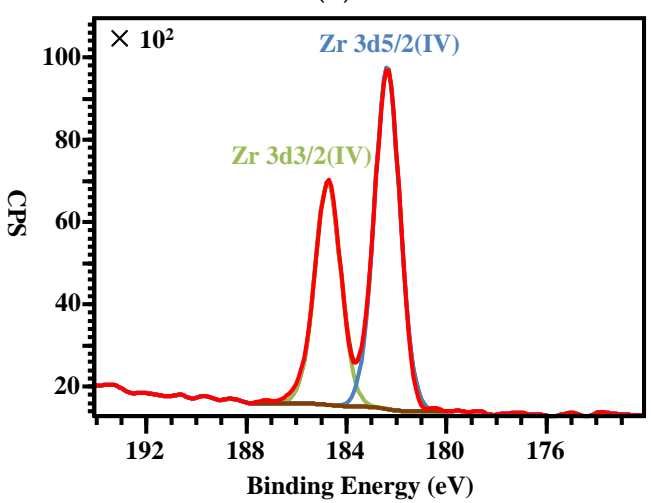

(c)

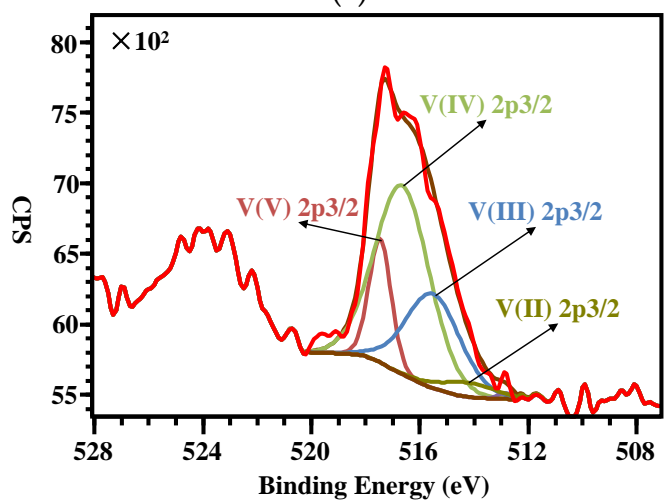

(e)

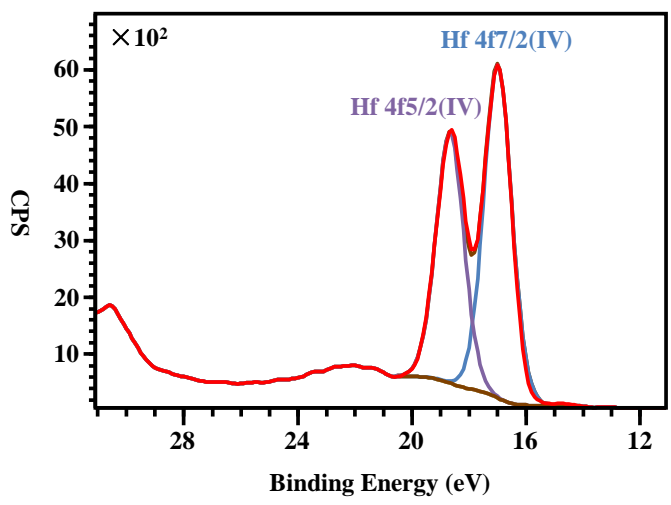

(g)

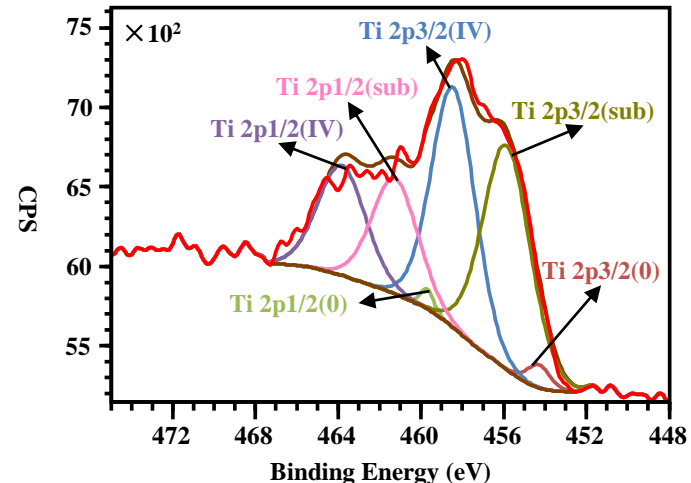

(b)

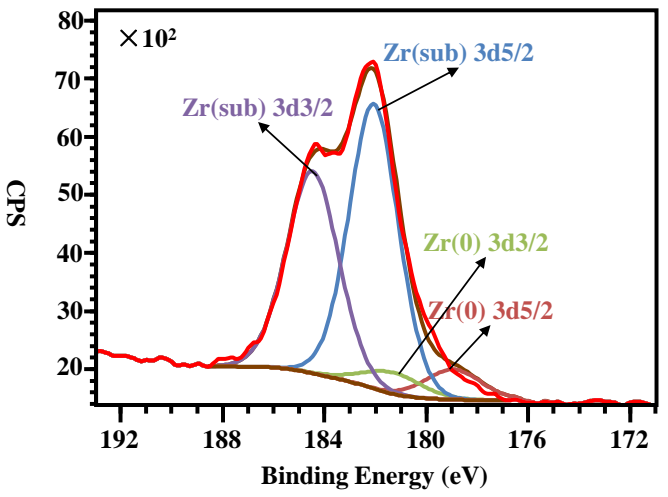

(d)

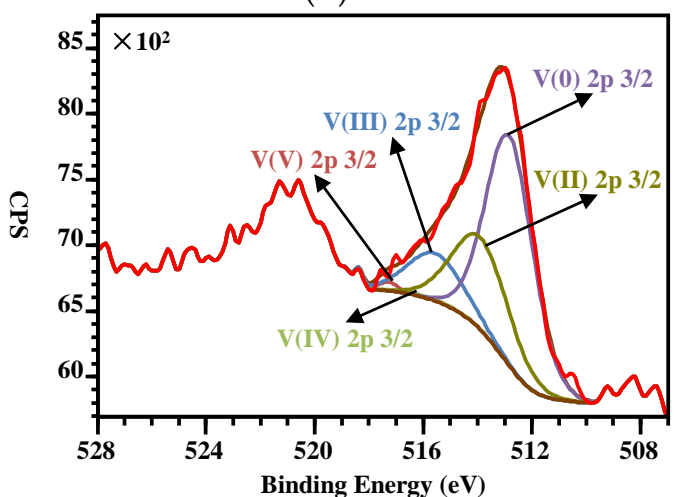

(f)

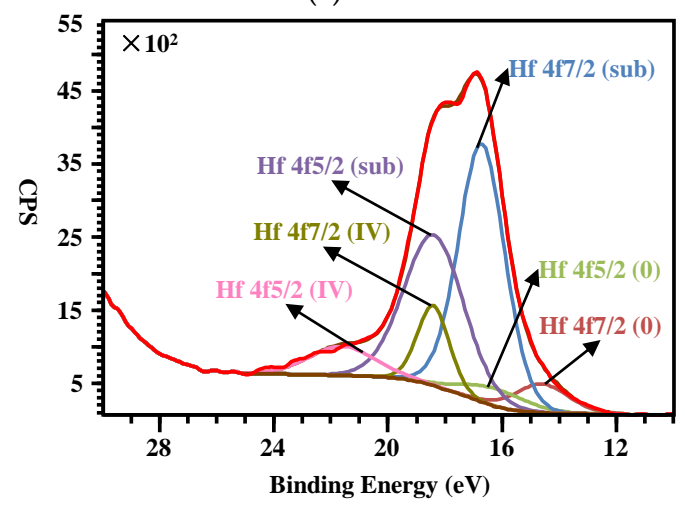

(h)

Figure 7. The XPS energy spectra of (a) $\mathrm{Ti},(\mathbf{c}) \mathrm{Zr},(\mathbf{e}) \mathrm{V}$ and (g) Hf tested at $25^{\circ} \mathrm{C}$ and (b) $\mathrm{Ti},(\mathbf{d}) \mathrm{Zr},(\mathbf{f}) \mathrm{V}$ and (h) Hf tested at $150{ }^{\circ} \mathrm{C}$ of the Ti-Zr-V-Hf film with OCMF substrates, respectively. 
The interpretation of the Hf $4 \mathrm{f}$ XPS spectra in Figure $7 \mathrm{~g}$, h was to determine the content ratios of the $\operatorname{Hf}(0), \operatorname{Hf}(\mathrm{sub})$ and $\mathrm{Hf}(\mathrm{IV})$ oxidation states to understand the activation process. The fitting results of the Hf $4 \mathrm{f}$ XPS spectrum tested at $25^{\circ} \mathrm{C}$ in Figure $7 \mathrm{~g}$ indicate that the Hf metal was basically oxidized on the surface of the Ti-Zr-V-Hf NEG film. The binding energy of Hf(IV) $4 f 7 / 2$ is $17.0 \mathrm{eV}$, which is in accordance with the reported references [42,43]. Whereas the spectrum of Hf $4 \mathrm{f}$ XPS spectrum tested at $150{ }^{\circ} \mathrm{C}$ shown in Figure $7 \mathrm{~h}$ demonstrates that the Hf metal, Hf suboxide and Hf oxide appeared with the percentages of 9.4 at $\%, 74.8$ at $\%$ and 15.8 at $\%$, respectively.

\section{Conclusions}

The OCMF material was first proposed in this paper to inhibit the SEE in accelerators or vacuum devices, etc. In addition, Ti-Zr-V-Hf NEG films were deposited on OCMF substrates for the first time to improve the pumping properties in a vacuum system.

First, the SEYs of the OCMF substrates before and after Ti-Zr-V-Hf NEG film deposition were evaluated by the SEY measurements. The SEY results indicate that OCMF is a very promising solution for reducing the $\delta_{\max }$ to below 1.25. After Ti-Zr-V-Hf NEG film deposition on the OCMF substrates, the $\delta_{\text {max }}$ further decreased to 1.22 , and then to 1.20 , following heating in a vacuum.

Second, OCMFs coated with a NEG film can also act as getter pumps to improve the vacuum. The analysis of the chemical states of Ti, Zr, V and Hf NEG films indicated a distinct valence state and atomic ratio changes during activation.

Finally, the related experimental results mentioned above demonstrate that the Ti-Zr-V-Hf NEG film deposited on the OCMF substrates can be activated and used as the getter pumps in the vacuum, also with the advantage of low SEY properties. With the advantages of low density and large contact areas, OCMF can be used for electron cloud mitigation and maintaining a high vacuum in accelerators or high-power microwave devices, etc.

Author Contributions: Conceptualization, J.W. and D.W.; data curation, J.W., J.Z., Y.G., Y.H., Z.Y. and Y.W.; funding acquisition, S.W. and Z.X.; investigation, J.W., J.Z., Y.X., S.Y. and D.W.; methodology, J.Z., Y.G., Z.Y., Y.X. and Y.W.; supervision, S.W. and Z.X.; validation, J.W., Y.G., Y.H., H.L. and S.Y.; writing-original draft, J.W.; writing-review and editing, H.L., S.W. and Z.X. All authors have read and agree to the published version of the manuscript.

Funding: This work was supported by the National Natural Science Foundation for the Youth of China No. 11905170, the Fundamental Research Funds for the Central Universities No. XJH012019018, Shanxi Natural Science Basic Research Program General Project (Youth) No. 2020JQ-001, Shanxi Province Postdoctoral Science Foundation Grant No. 2018BSHEDZZ05, China Postdoctoral Science Foundation Grant No. 2018M643667, the National Natural Science Foundation of China under Grant No. 11775166 and National key R \& D program 2017YFF0104201.

Acknowledgments: We would like to also thank Jiamei Liu at the Instrument Analysis Center of Xi'an Jiaotong University for her assistance with XPS tests.

Conflicts of Interest: The authors declare no conflict of interest.

\section{References}

1. Anashin, V.V.; Collins, I.R.; Dostovalov, R.V.; Fedorov, N.V.; Krasnov, A.A.; Malyshev, O.B.; Ruzinov, V.L. Comparative study of photodesorption from TiZrV coated and uncoated stainless steel vacuum chambers. Vacuum 2004, 75, 155-159. [CrossRef]

2. Mahner, E.; Hansen, J.; Küchler, D.; Malabaila, M.; Taborelli, M. Ion-stimulated gas desorption yields of electropolished, chemically etched, and coated ( $\mathrm{Au}, \mathrm{Ag}, \mathrm{Pd}, \mathrm{TiZrV})$ stainless steel vacuum chambers and St707 getter strips irradiated with 4.2 MeV/u lead ions. Phys. Rev. Spec. Top. Accel. Beams 2005, 8, 053201. [CrossRef]

3. Ferreira, M.J.; Seraphim, R.M.; Ramirez, A.J.; Tabacniks, M.H.; Nascente, P.A.P. Characterization and evaluation of Ti-Zr-V non-evaporable getter films used in vacuum systems. Phys. Proced. 2012, 32, 840-852. [CrossRef]

4. Singleton, J.H. Hydrogen pumping by sputter-ion pumps and getter pumps. J. Vac. Sci. Technol. 1971, 8, 275. [CrossRef] 
5. Sutara, F.; Skala, T.; Masek, K.; Matolin, V. Surface characterization of activated Ti-Zr-V NEG coatings. Vacuum 2009, 83, 824-827. [CrossRef]

6. Ferreira, M.J.; Tallarico, D.A.; Nascente, P.A.P. Preparation and characterization of Ti-Zr-V non-evaporable getter films to be used in ultra-high vacuum. AIP Conf. Proc. 2009, 1092, 168-172.

7. Benvenuti, C.; Santana, A.E.; Ruzinov, V. Ultimate pressures achieved in TiZrV sputter-coated vacuum chambers. Vacuum 2001, 60, 279-284. [CrossRef]

8. Wang, J.; Gao, Y.; Fan, J.; You, Z.; Wang, S.; Xu, Z. Study on the effect of laser parameters on the SEY of aluminum alloy. IEEE Trans. Nucl. Sci. 2019, 66, 609-615. [CrossRef]

9. Pivi, M.; King, F.K.; Kirby, R.E.; Raubenheimer, T.O.; Stupakov, G.; le Pimpec, F. Sharp reduction of the secondary electron emission yield from grooved surfaces. J. Appl. Phys. 2008, 104, 104904. [CrossRef]

10. Costa Pinto, P.; Calatroni, S.; Neupert, H.; Letant-Delrieux, D.; Edwards, P.; Chiggiato, P.; Taborelli, M.; Vollenberg, W.; Yin-Vallgren, C.; Colaux, J.L.; et al. Carbon coatings with low secondary electron yield. Vacuum 2013, 98, 29-36. [CrossRef]

11. Le Pimpec, F.; Kirby, R.E.; King, F.K.; Pivi, M. The effect of gas ion bombardment on the secondary electron yield of TiN, TiCN and TiZrV coatings for suppressing collective electron effects in storage rings. Nucl. Instrum. Methods Phys. Res. Sect. A 2006, 564, 44-50. [CrossRef]

12. Kim, H.C.; Huh, S. Porous carbon-based supercapacitors directly derived from metal-organic frameworks. Materials 2020, 13, 4215. [CrossRef] [PubMed]

13. Lee, J.; Choi, Y.C. Pore structure characteristics of foam composite with active carbon. Materials 2020, $13,4038$. [CrossRef]

14. Monkova, K.; Vasina, M.; Monka, P.P.; Kozak, D.; Vanca, J. Effect of the pore shape and size of 3D-Printed open-porous ABS materials on sound absorption performance. Materials 2020, 13, 4474. [CrossRef]

15. Davies, G.J.; Zhen, S. Metallic foams their production properties and applications. J. Mater. Sci. 1983, 18, 1899-1911. [CrossRef]

16. Calmidi, V.V.; Mahajan, R.L. Forced convection in high porosity metal foams. J. Heat Transfer 2000, 122, 557-565. [CrossRef]

17. Gaitanaros, S.; Kyriakides, S. Dynamic crushing of aluminum foams: Part II-Analysis. Int. J. Solids Struct. 2014, 51, 1646-1661. [CrossRef]

18. Mun, J.; Jeon, H.; Jeong, B.; Jung, J. Decomposition of endothermic fuel using washcoated HZSM-5 on metal foam. Catal. Today 2020. [CrossRef]

19. August, A.; Nestler, B. About the surface area to volume relations of open cell foams. Eng. Res. Express 2020, 2, 015021. [CrossRef]

20. Liu, R.; Tan, Y.; Gong, F.; Li, X.; Dai, L.; Yang, J.; Xu, S.; Li, G. The application of porous foam structure cooling arrangement system for a thin disk laser. Optik 2020, 200, 163423. [CrossRef]

21. Liu, J.; Gao, Y.; Fan, Y.; Zhou, W. Fabrication of porous metal by selective laser melting as catalyst support for hydrogen production microreactor. Int. J. Hydrogen Energy 2020, 45, 10-22. [CrossRef]

22. Mohamed Moussa, E.I.; Karkri, M. A numerical investigation of the effects of metal foam characteristics and heating/cooling conditions on the phase change kinetic of phase change materials embedded in metal foam. J. Energy Storage 2019, 26, 100985. [CrossRef]

23. Banhart, J.; Ashby, M.; Fleck, N. Metal foams and porous metal structures. In Proceedings of the International Conference on Cellular Metals and Metal Foaming Technology, Bremen, Germany, 14-16 June 1999.

24. Banhart, J. Manufacture, characterisation and application of cellular metals and metal foams. Prog. Mater. Sci. 2001, 46, 559-632. [CrossRef]

25. Kulshreshtha, A.; Dhakad, S.K. Preparation of metal foam by different methods: A review. Mater. Today Proc. 2020, 26, 1784-1790. [CrossRef]

26. Köhl, M.; Habijan, T.; Bram, M.; Buchkremer, H.P.; Stöver, D.; Köller, M. Powder metallurgical near-net-shape fabrication of porous NiTi shape memory alloys for use as long-term implants by the combination of the metal injection molding process with the space-holder technique. Adv. Eng. Mater. 2009, 11, 959-968. [CrossRef]

27. Levine, B.R.; Fabi, D.W. Porous metals in orthopedic applications-A review. Materialwiss. Werkstofftech. 2010, 41, 1001-1010. [CrossRef] 
28. Kaz'mina, O.V.; Suslyaev, V.I.; Dorozhkin, K.V.; Kaimonov, M.R.; Stebeneva, V.I. Effect of a coating deposited on foam glass on the ability to absorb high-frequency electromagnetic radiation. Glass Ceram. 2018, 75, 230-233. [CrossRef]

29. Leong, K.C.; Jin, L.W. Effect of oscillatory frequency on heat transfer in metal foam heat sinks of various pore densities. Int. J. Heat Mass Transfer 2006, 49, 671-681. [CrossRef]

30. Malyshev, O.B.; Valizadeh, R.; Hogan, B.T.; Hannah, A.N. Electron-stimulated desorption from polished and vacuum fired 316LN stainless steel coated with Ti-Zr-Hf-V. J. Vac. Sci. Technol. A 2014, 32, 061601. [CrossRef]

31. Baglin, V.; Collins, I.; Henrist, B.; Hilleret, N.; Vorlaufer, G. A summary of main experimental results concerning the secondary electron emission of copper. LHC Proj. Rep. 2002, 472, 15.

32. Bojko, I.; Hilleret, N.; Scheuerlein, C. Influence of air exposures and thermal treatments on the secondary electron yield of copper. J. Vac. Sci. Technol. A 2000, 18, 972-979. [CrossRef]

33. Furman, M.A.; Chaplin, V.H. Update on electron-cloud power deposition for the LHC arc dipoles. Phys. Rev. Spec. Top. Accel. Beams 2006, 9, 034403. [CrossRef]

34. Wang, Y.; Wang, J.; Xu, Y.; Zhang, Y.; Zhang, B.; Wei, W.; Zhang, T. Research on Low Secondary Electron Yield Materials for Future Accelerators; JACOW: Geneva, Switzerland, 2016; pp. 3284-3286.

35. Ermolieff, A.; Bernard, P.; Marthon, S.; Wittmer, P. Nitridation of polycrystalline titanium as studied by in situ angle-resolved X-ray photoelectron spectroscopy. Surf. Interface Anal. 1988, 11, 563-568. [CrossRef]

36. Badrinarayanan, S.; Sinha, S.; Mandale, A.B. XPS studies of nitrogen ion implanted zirconium and titanium. J. Electron Spectrosc. Relat. Phenom. 1989, 49, 303-309. [CrossRef]

37. Siemensmeyer, B.; Bade, K.; Schultze, J.W. XPS and electrochemical studies of thin TiN Layers. Ber. Bunsenges. Phys. Chem. 1991, 95, 1461-1469. [CrossRef]

38. Slinkard, W.E.; Degroot, P.B. Vanadium-titanium oxide catalysts for oxidation of butene to acetic acid. J. Catal. 1981, 68, 423-432. [CrossRef]

39. Burke, A.R.; Brown, C.R.; Bowling, W.C.; Glaub, J.E.; Kapsch, D.; Love, C.M.; Whitaker, R.B.; Moddeman, W.E. Ignition mechanism of the titanium-boron pyrotechnic mixture. Surf. Interface Anal. 1988, 11, 353-358. [CrossRef]

40. Leinen, D.; Lassaletta, G.; Fernández, A.; Caballero, A.; González-Elipe, A.R.; Martín, J.M.; Vacher, B. Ion beam induced chemical vapor deposition procedure for the preparation of oxide thin films. II. Preparation and characterization of AlxTiyOz thin films. J. Vac. Sci. Technol. A 1996, 14, 2842-2848. [CrossRef]

41. Balaceanu, M.; Braic, M.; Braic, V.; Vladescu, A.; Negrila, C.C. Surface chemistry of plasma deposited ZrC hard coatings. J. Optoelectron. Adv. Mater. 2005, 7, 2557-2560.

42. Chourasia, A.R.; Hickman, J.L.; Miller, R.L.; Nixon, G.A.; Seabolt, M.A. X-Ray photoemission study of the oxidation of Hafnium. Int. J. Spectrosc. 2009, 2009, 439065. [CrossRef]

43. Dey, S.K.; Das, A.; Tsai, M.; Gu, D.; Floyd, M.; Carpenter, R.W.; de Waard, H.; Werkhoven, C.; Marcus, S. Relationships among equivalent oxide thickness, nanochemistry, and nanostructure in atomic layer chemical-vapor-deposited Hf-O films on Si. J. Appl. Phys. 2004, 95, 5042-5048. [CrossRef]

Publisher's Note: MDPI stays neutral with regard to jurisdictional claims in published maps and institutional affiliations.

(C) 2020 by the authors. Licensee MDPI, Basel, Switzerland. This article is an open access article distributed under the terms and conditions of the Creative Commons Attribution (CC BY) license (http://creativecommons.org/licenses/by/4.0/). 